\title{
Non-Exclusion Effects in Aqueous Size-Exclusion Chromatography of Polysaccharides
}

\author{
Azamat Solievich Boymirzaev ${ }^{1}$, Abbaskhan Sabirkhanovich Turaev ${ }^{2}$ \\ ${ }^{1}$ Department of Mechanical-Technology, Namangan Engineering-Economic Institute, Namangan, Uzbekistan \\ ${ }^{2}$ O.Sadikov Institute of Bioorganic Chemistry Uzbek Academy of Sciences, Tashkent, Uzbekistan \\ E-mail:azamat58@mail.ru \\ Received January 10, 2010; revised April 29, 2010; accepted May 10, 2010
}

\begin{abstract}
This paper concerned to investigation of aggregate formation processes in aqueous Size-exclusion chromatography (SEC) of Na-carboxymethylcellulose (Na-CMC).
\end{abstract}

Keywords: SEC, Na Carboxymethylcellulose, Aggregate Formation

\section{Introduction}

Size-exclusion chromatography is one of the powerful methods for determination and investigation of molecular weight distribution of polymers [1]. In aqueous SEC of polymers [2], the understanding of the separation mechanism demands much more attention due to the enthalpy interactions distorting a pure size-exclusion separation mechanism [1]. Because of the presence of polar, and often anionic, groups in the stationary phases used in SEC, the mobile phase must be carefully chosen to repress polymer-gel and intermolecular interactions. This is particularly important in SEC of polyelectrolytes and polar molecules such as carbohydrates [3]. Suppression of interactions, such as polyelectrolyte expansion, ion-exclusion, molecular adsorption and aggregate formation depends on nature of electrolyte, optimal value of $\mathrm{pH}$ and ionic strength of eluent.

The aim of this paper is to investigate of aggregate formation process in SEC of Na-CMC in order to determine of the suitable aqueous eluent for true size-exclusion separation mechanism of macromolecules.

\section{Materials and Methods}

SEC was performed on the liquid chromatograph, consisting from syringe pump Merk-Hitachi L-6000A model, Shodex RI-101 refractive index detector, multiangle laser light scattering detector DAWN NSP (Watt technology), manual sample injector Rheodine 2104, degasser of eluent and two chromatographic columns PL Aquagel-OH Mixed termostated at $25^{\circ} \mathrm{C}$ and connected in series. Synthesis of Na-CMC was described in [4]. SEC analysis were performed using two types of eluent: $\mathrm{NaCl}$ and $\mathrm{NaNO}_{3}$ in the water with concentration $0.1 \mathrm{~mol} / \mathrm{L}$.

\section{Results and Discussion}

Many of hydrophilic polymers are polyelectrolytes and, therefore, their elution properties in SEC is complicated by various non-exclusion effects, such as ion exclusion, polyelectrolyte expansion, molecular adsorption, and aggregate formation, which distort the normal SEC separation mechanism. These effects can be eliminated by increasing the ionic strength and changing the $\mathrm{pH}$ of the eluent so as to decrease the degree of dissociation of ionic groups both in the macromolecular chain and on the sorbent surface [5]. Physicochemical properties such as structure, molecular weight and shape or conformation are primary factors controlling their functional properties. A typical molar mass sensitive detector is a multi angle laser light scattering (MALLS). This detector has the advantage of providing structural information in addition to the molar masses. Analysis of CMC by SEC in $0.1 \mathrm{M}$ $\mathrm{NaNO}_{3}$ solutions were complicated by presence of the low amount associates forming due to intermolecular interactions [6,7]. To avoid of the aggregates of macromolecules Hoogendam C.W. [7] demonstrated that the solutes $\mathrm{Na}-\mathrm{CMC}$ in first step were prepared in pure water, after $0.1 \mathrm{M} \mathrm{NaNO}_{3}$ were added to sample solution. We have received bimodal chromatograms of CMC from MALLS detector in SEC analysis when used of water consisting $\mathrm{NaNO}_{3}$ with concentration $0.1 \mathrm{~mol} / \mathrm{L}$ (Figure 1(a)). Same result was occurring, when we used $0.1 \mathrm{M} \mathrm{NaNO}_{3}$ in water as eluent. But when $0.1 \mathrm{M} \mathrm{NaCl}$ was used first peak in the chromatogram is disappeared indicating that 


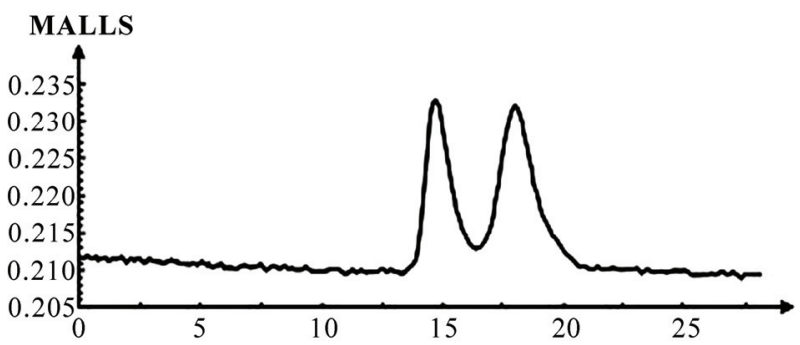

(a)

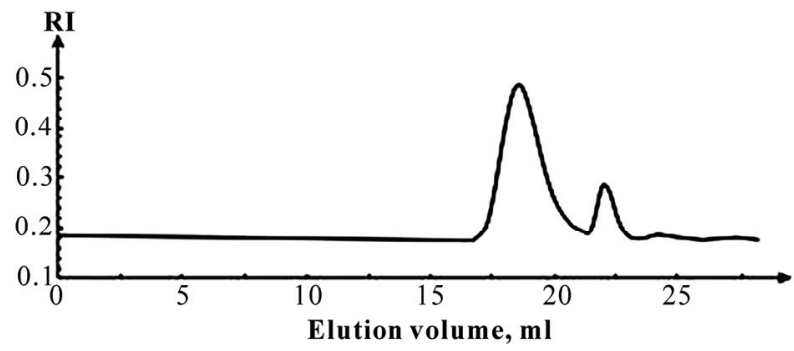

(b)

Figure 1. Gel chromatograms of the Na-CMC $\left(M_{w}=2.18 \times 10^{4}\right)$ received from MALLS (a) and RI detector (b) in $0.1 \mathrm{M}$ $\mathrm{NaNO}_{3}$

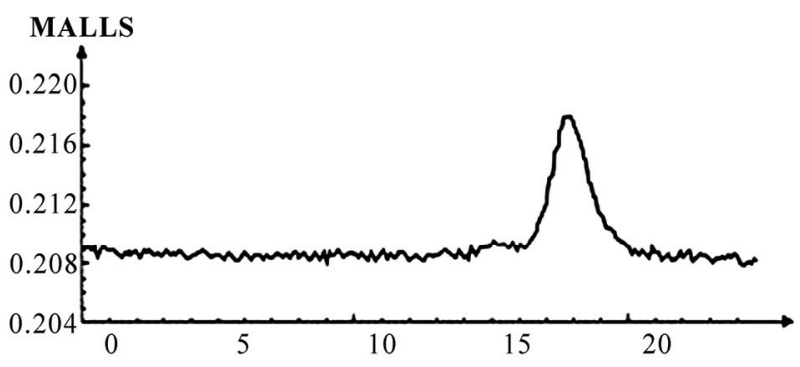

(a)

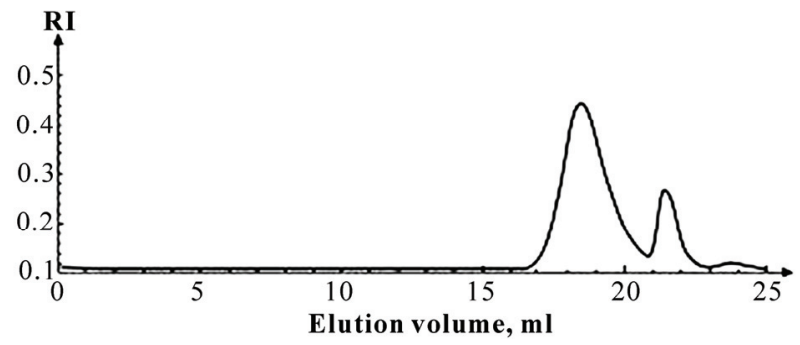

(b)

Figure 2. Gel chromatograms of the Na-CMC $\left(\mathrm{M}_{\mathrm{w}}=\mathbf{2 . 1 8} \times 10^{4}\right)$ received from MALLS (a) and RI detector (b) in $0.1 \mathrm{M}$ NaCl.

formation of molecular aggregates not realized and further investigations on SEC of cellulose derivatives were conducted using $0.1 \mathrm{M} \mathrm{NaCl}$ in water (Figure 2(a)). Second, the presence of microgels as a result of small but significant amounts of very high molecular weight $\mathrm{CMC}$ was detected using a MALLS detector as first peak in chromatogram. However, the microgel was detected by the refractive index detector (Figures $\mathbf{1}$ and 2(b)) as very small peak, suggesting that this detector responds as if to a true polymeric solution.

\section{Conclusions}

Specific polymer-solvent and intermolecular interactions in aqueous SEC can lead to formation of aggregates of $\mathrm{Na}-\mathrm{CMC}$ in $0.1 \mathrm{M} \mathrm{NaNO}_{3}$. Dual detection in SEC allows determining and evaluating of degree of formation of the aggregates. In SEC of Na-CMC low amount of aggregates in $0.1 \mathrm{M} \mathrm{NaNO}_{3}$ was detected. To eliminate of aggregates and realize pure SEC separation mechanism of $\mathrm{Na}-\mathrm{CMC}$ we are recommend use of $0.1 \mathrm{M} \mathrm{NaCl}$ as eluent.

\section{References}

[1] S. Mori and H. Barth, "Size Exclusion Chromatography," Springer Verlag, Berlin, Heidelberg, 1999, p. 234.

[2] J. Desbrieres, J. Mazet and M. Rinaudo, "Gel Permeation Chromatography on Polyelectrolytes in Aqueous Solution," European Polymer Journal, Vol. 18, No. 3, 1982, pp. 269-272.

[3] S. C. Churms, "Modern Size-Exclusion Chromatography of Carbohydrates and Gly-Coconjugates," Journal of Chromatography, Vol. 66, 2002, pp. 267-303.

[4] S. Shomuratov, E. A. Murodov and A. S. Turaev, "Synthesis and Investigation of Prolonged Preparation on the Basis of Carboxymethylcellulose," Journal of Pharmacia, Vol. 4, 2005, p. 61.

[5] M. Rinaudo and B. J. Tinland, "Some Problems in Aqueous Size-Exclusion Chromatography of Synthetic Polymer and Biopolymer Characterization," Journal of Applied Polymer Science. Applied Polymer Symposium, Vol. 48, 1991, p. 19.

[6] L. Picton, L. Merle and Muller, "Solution Behavior of Hydrofobically Accociating Cellulose Derivatives," International Journal of Polymer Analysis and Characterization, Vol. 2, No. 2, 1996, pp. 103-113.

[7] C. W. Hoogendam, A. de Keizer, M. A. C. Stuart, B. H. Bijsterbosch, J. A. M. Smit, J. A. P. P. van Dijk, P. M. van der Horst and J. G. Batelaan, "Persistence Length of Carboxymethyl Cellulose as Evaluated from Size Exclusion Chromatography and Potentiometric Titrations," Macromolecules, Vol. 31, No. 18, 1998, pp. 6297-6309. 